\title{
The waves amplitudes increase due to interacting with thermocapillary structures
}

\author{
Evgeniy Shatskiy, Yuliya Koemets, Evgeny Chinnov \\ Kutateladze Institute of Thermophysics SB RAS, Lavrent'ev av. 1, Novosibirsk, 630090, Russia \\ Novosibirsk State University, 630090 Novosibirsk, Russia
}

\begin{abstract}
The analysis of experimental data on the simultaneous measurement of the thickness and temperature fields in the flowing heated liquid film at $\operatorname{Re}=15$ is presented. It is shown that increasing heat flux results in more expressed rivulet formation in the lower part of the heater (differential thicknesses in the rivulet and interrivulet area increases from $0.04 \mathrm{~mm}$ to 0.11 $\mathrm{mm})$. It was found that the wave amplitude increase in the region where waves interact with the thermocapillary structures.
\end{abstract}

\section{Introduction}

Fluid film flows are widely used in cooling of the heat-generating surfaces in many technological applications: heat exchangers, condensers, evaporators. The main characteristics of these flows are their wavy amplitudes and structures. It is known that two-dimensional hydrodynamic waves in an isothermal liquid film are unstable to three-dimensional disturbances. It was found that the wavelength of the instability to transverse three-dimensional perturbations decreases with increasing Reynolds number. During breakdown of two-dimensional into three-dimensional waves in $[1,2]$ it was shown that there are isolated synchronous wave when there is no phase shift in the transverse direction of waves and the subharmonic waves, when the phase shift occurs.

When the liquid film flow over the heated surface except hydrodynamic instability that leads to the development of three-dimensional waves, there is also a thermocapillary instability which results in the appearance on the film surface of the stationary three-dimensional structures in the form of a number of rivulets with a thin film between them. Various regimes of the structures formation in a heated falling liquid film were discovered in [3-5]. Depending on the heating conditions and the temperature gradient on the film surface there are two types of thermo-capillary structures. Two mechanisms of growth of the relative amplitudes of the waves when heated falling liquid film are known in the literature: in the residual layer of the liquid film because of its intensive evaporation [6] and the film thickness decreases in interjet region by the action of thermocapillary forces [7].

\section{Experimental setup}

The setup is a closed circulation loop containing a reservoir with a pump, test section, filters, flow meters, pipes and valves. The test section consists of a carrier plate, a filmformer, a heat stabilizer, and a heater. The working fluid (water with dissolved rhodamine $6 \mathrm{G}$ as a dye) supplies by a pump in filmformer that included the collection chamber and the dispenser with a calibrated nozzle. The liquid 
flows down on the plate and then goes back into the reservoir. For the investigated conditions of the flow of a film of liquid, the formation of rivulets and propagation of developed threedimensional waves over the surface along the heater was observed. It has been shown in [8] that, for the isothermal case, the transition from a twodimensional wave motion to a threedimensional one on vertically falling films of liquid is accompanied by a redistribution of liquid in the horizontal direction. In a film of liquid being heated, the redistribution of liquid increases considerably due to the influence of thermocapillary forces. The formation of rivulets and of a thin film between them occurs [9]. The parameters of hydrodynamic waves are significantly varied when they pass along the heater.

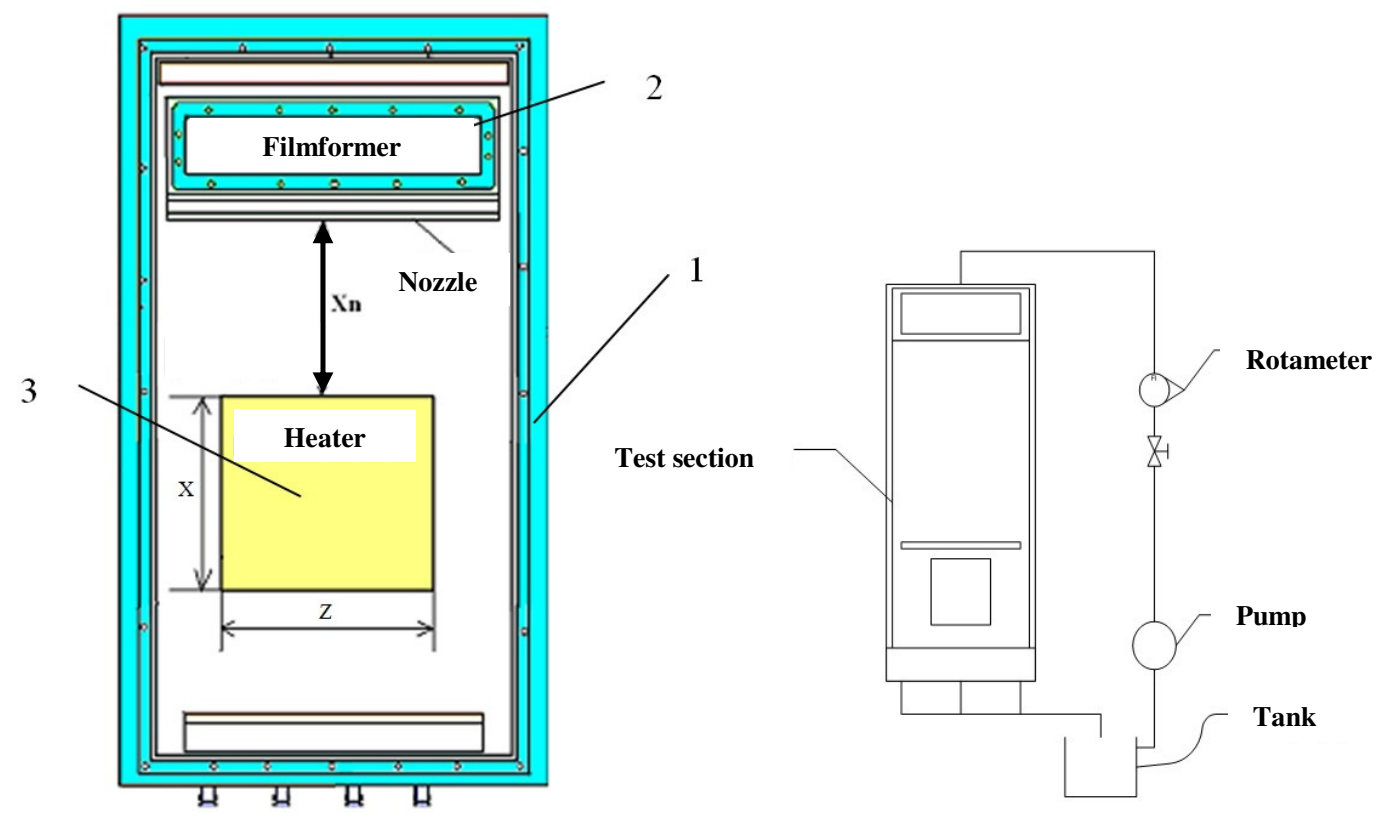

Figure 1: Experimental setup: 1 - Test section; 2 - filmformer; 3 - heater.

The filmformer locates in the upper part of the test section. The distance from the bottom edge of the nozzle to the upper edge of the heater is $263 \mathrm{~mm}$, which corresponds to the area of transition from two-dimensional to three-dimensional waves. The heating element is a flat copper heat exchanger $150 \mathrm{~mm}$ wide and $100 \mathrm{~mm}$ long. Inside the heater, there are rectangular channels through which the heating liquid is pumping. The heat flux from the heater surface is calculated from the temperature difference of pumping fluid on the inlet and outlet of the heat exchanger for a given mass flow rate. The temperature of the heater surface facing the film was measured by three thermocouples located on the vertical axis of symmetry. The boundary condition on the surface is close to $\mathrm{T}=\mathrm{const}$ providing high value of temperature gradients near the upper edge of the heater. The heat flux varied in the range $0.5-6 \mathrm{~W} / \mathrm{cm}^{2}$. The initial water temperature at the nozzle exit was $28{ }^{\circ} \mathrm{C}$. The film Reynolds number equals to 15 . For determination of the instantaneous field of film thickness and wave characteristics, a modified fluorescent method is used. A distinctive feature of the layout of the measuring system in the experiment is the location of the radiation source and the receiver from the free surface of the film. To energise the fluorophore the laser diode pumping is used (RLM-5322000). The laser continuously illuminating an area with the size of $120 \times 120 \mathrm{~mm}$. Re-emmited light is recording with a digital camera PCO $1200 \mathrm{~h}$, with a frequency of $500 \mathrm{~Hz}$ in full frame $(1280 \times 1024$ pix.). Before the camera, there is a red filter to cut off the reflected laser light. When measured in the area of $100 \times 100 \mathrm{~mm}$, the system provides a spatial resolution of $0.1 \mathrm{~mm}$. 


\section{Results and discussion}

Figure 1 shows the dependence of the amplitude of the incoming waves to the heater along the rivulet from the path length for several values of the heat flux. It is seen that with increasing of the heat flux there is a local maximum of the thickness in the initial part of the heater. This trend is related to the fact that when the heat flux reaches the threshold value at the upper edge of the heater in the residual layer there are thermocapillary periodic structures. These structures arise because of the high temperature gradients at the leading edge of the heater (up to $10 \mathrm{~K} / \mathrm{mm}$ ), resulting in occurrence of thermocapillary forces directed against the flow. These structures make a disturbance in the following wave front, leading to an increase in the amplitude of the waves. It was found that the amplitude of hydrodynamic waves in the upper part of the heater $(5 \mathrm{~mm}<\mathrm{X}<30 \mathrm{~mm})$ can be increased by more than half when interacting with the thermocapillary instability of type $\mathrm{A}\left(\mathrm{q}=2.55 \mathrm{~W} / \mathrm{cm}^{2}\right)$. While moving along the heater the wave amplitude decreases, although the value is substantially higher than at lower heat flux $\left(\mathrm{q}=0.98 \mathrm{~W} / \mathrm{cm}^{2}\right)$ when thermocapillary structure type A are not yet formed. Also at high heat fluxes there is a transverse movement of the rivulets and in combination with an amplitude increase it results in an increase of the stability of the heated liquid film to rupture.

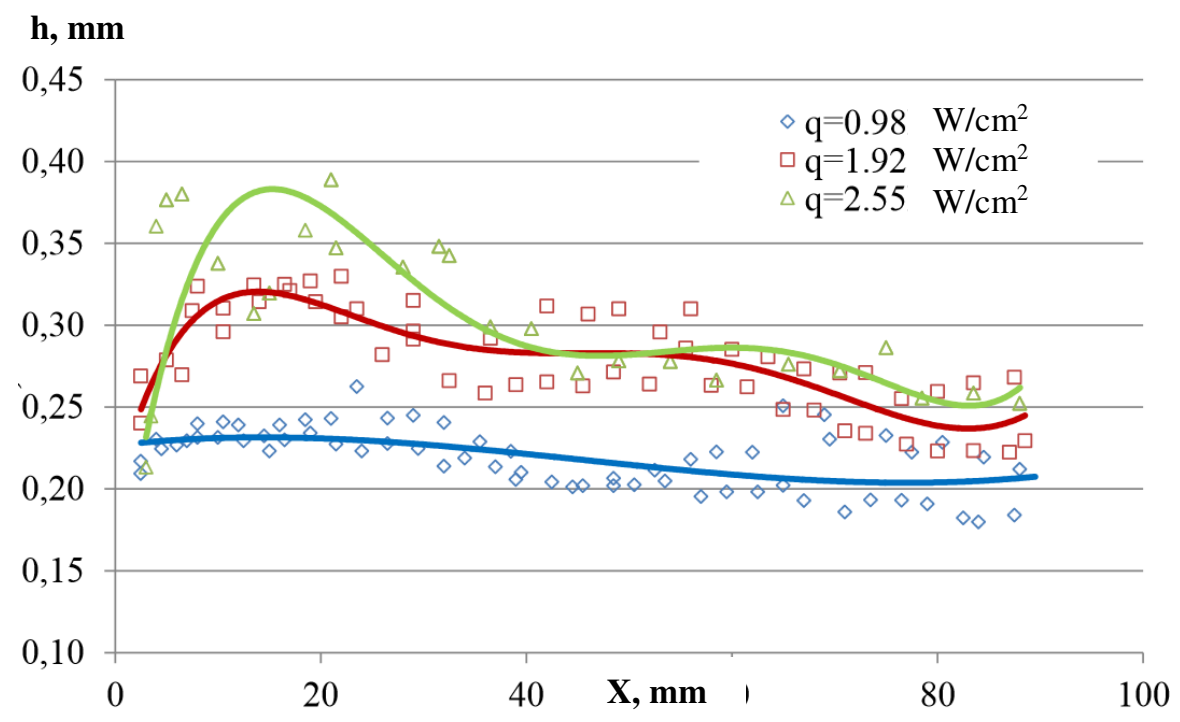

Figure 2: Dependence of the amplitude of the wave from the path length of the heater

This work was supported by a grant from the Russian Science Foundation (project Nr. 15-1930038).

\section{References}

1. Joo S. W., Davis S.H. J. Fluid Mech. 242. 529-547 (1992).

2. Liu J., Schneider J. B., Golub J.P. Phys. Fluids. 7. 55-67 (1995).

3. O.A. Kabov, Heat Transfer Research, 27, 221-226 (1996)

4. O.A. Kabov, I.V. Marchuk, V.M. Chupin, Russ. J. Eng. Thermophys. 6 (2) 104-138 (1996).

5. O.A. Kabov, E.A. Chinnov, Russ. J. Eng. Thermophys. 7 (1/2) 1-34 (1997).

6. Pavlenko A. N. et. al. Journal of Engineering Thermophysics. 11, 321 - 333 (2002) 
7. Chinnov E. A. International Journal of Heat and Mass Transfer, 71, 106-116.

8. S. V. Alekseenko, V. V. Guzanov, D. M. Markovich, and S. M. Kharlamov. Technical Physics Letters, 38, 739-742.

9. Chinnov E.A., Nazarov A.D., Saprykina A.V., Zhukovskaya O.V., Serov A.F. High Temperature, 45, 657-664. 